\title{
HEGEMONIA DISCURSIVA E CONSENSO ATIVO
}

\author{
DISCURSIVE HEGEMONY AND ACTIVE CONSENSUS
}

\author{
HEGEMONÍA DISCURSIVA Y CONSENSO ACTIVO
}

\author{
Solange Martins Oliveira Magalhães* \\ Jackeline Império Soares**
}

\begin{abstract}
Resumo: O tortuoso e difícil processo de questionamento sobre o trabalho docente passa pela análise do desenvolvimento do sujeito social, o qual exige para sua efetivação a relação trabalhoeducação como atributos da humanização. A origem do homem e da educação coincide, mas o trabalho é a característica essencial que define o homem em sua totalidade. O que o homem é, é-o pelo trabalho; com ele se desenvolve, se aprofunda e se complexifica ao longo do tempo. A partir de uma perspectiva histórico-crítica, que destaca os aspectos ontológico e histórico dos fenômenos estudados, elegemos a categoria trabalho-educação para entender o processo que orienta e alimenta o trabalho docente, como atividade que tem a potência de desenvolver sujeitos emancipados, participantes críticos da vida da sociedade. Para compreender a relação trabalho-educação, tomamos a produção acadêmica publicada na ANPEd, no recorte período 2009-2013, do Grupo de Trabalho (GT): Formação de Professores, como representativa dos discursos acadêmicos. Analisamos o posicionamento epistemológico e político dos artigos, assumidamente críticos e dialéticos, destacando como sustentam a relação trabalho-educação. Os resultados à presença de hegemonia discursiva, quando críticos contra-hegemônicos visam à qualidade social para a educação, preocupam-se com o desenvolvimento de processos e potencialidades dos sujeitos, inserindo-os em atividades que possibilitam a apropriação de conhecimentos, com vistas tanto à qualificação teórico-técnica quanto à compreensão crítica das posturas baseadas na ética das relações assimétricas e da produção da submissão nos indivíduos via trabalho docente: quando hegemônicos, fortalecem o consenso ativo.
\end{abstract}

Palavras-chave: Trabalho docente. Posicionamento epistemológico. Dialética. Consenso ativo.

\begin{abstract}
The tortuous and difficult process of questioning about the teaching job is an assessment of the development of the social being, understanding that this requires for its implementation the relationship between work and education as attributes of humanization. The origin of mankind and education coincide, but work is the essential defining characteristic

* Doutora em Educação, Faculdade de Educação, Universidade Federal de Goiás. Pesquisa financiada: CAPES/ CNPq/FAPEG. E-mail solufg@hotmail.com

** Especialista em Docência Universitária, Faculdade de Educação, Universidade Federal de Goiás. Agência Financiadora: CAPES/CNPq/FAPEG. E-mail jackelineufg@gmail.com
\end{abstract}


of man in its entirety. What man is, it is because his work; with it he deeply develops himself and becomes more complex over time. From a historical critical perspective that highlights the ontological and historical aspects of the phenomena studied, we chose to work with Education to understand the process that guides and nurtures teaching as an activity that has the potential to develop emancipated people, critical participants of life society. To understand the relationship between work and education, we take as the study object the academic content published in ANPEd in the period of 2009-2013, of the Working Group (WG): Teacher Education, as representative of academic discourse. We analyze the epistemological and political positioning of the articles, which are openly critical and dialectical, highlighting how to support the relationship between work and education. The result under discursive hegemony analysis, when critical counter-hegemonic, aims at social quality for education and it concerns with the development of processes and potentials of the social beings, inserting them into activities which enable the acquisition of knowledge, in order both to theoretical and technical qualification, as well as to critically understand the attitudes based on ethics of asymmetrical relations of production and submission in individuals by teaching; when it is hegemonic, it strengthens their active consensus.

Keywords: Teaching work. Epistemological positioning. Dialectics. Active consensus.

Resumen: El tortuoso y difícil proceso de cuestionamiento sobre el trabajo docente pasa por el análisis del desarrollo del sujeto social, lo cual exige para su efectuación la relación trabajo-educación como atributos de la humanización. El origen del hombre y de la educación coincide, pero el trabajo es la característica esencial que define el hombre en su totalidad. Lo que el hombre es, es por el trabajo; con él se desarrolla, se profundiza y se queda complejo a lo largo del tiempo. A partir de una perspectiva histórico-crítica, que destaca los aspectos ontológico e histórico de los fenómenos estudiados, elegimos la categoría trabajo-educación para entender el proceso que orienta y alimenta el trabajo docente, como actividad que tiene la potencia de desarrollar sujetos emancipados, participantes críticos de la vida de la sociedad. Para comprender la relación trabajo-educación, tomamos la producción académica publicada en la ANPEd, en el recorte periodo 2009-2013, del Grupo de Trabajo (GT): Formación de Profesores, como representativa de los discursos académicos. Analizamos el posicionamiento epistemológico y político de los artículos, asumidamiente críticos y dialécticos, destacando como sostienen la relación trabajo-educación. Los resultados a la presencia de hegemonía discursiva, cuando críticos contra-hegemónicos visan a la cualidad social para la educación, se preocupan con el desarrollo de procesos y potencialidades de los sujetos, los insiriendo en actividades que posibiliten la apropiación de conocimientos, con vistas tanto a la cualificación teórico-técnica cuanto a la comprensión crítica de las posturas basadas en la ética de las relaciones asimétricas y de la producción de la sumisión en los individuos vía trabajo docente: cuando hegemónicos fortalecen el consenso activo.

Palabras-clave: Trabajo docente.Posicionamiento epistemológico. Dialéctica. Consenso activo. 


\section{Introdução}

Conforme o posicionamento histórico-crítico, todo ser humano nasce candidato à humanização. O homem não nasce homem. Ele necessita aprender a ser homem; precisa ser hominizado para tornar-se representante da espécie homo sapiens. O humanizar-se também passa por aprender a produzir sua própria existência por meio do trabalho. Isso exige aprender, isto é, ele precisa do processo educativo.

Na mesma base teórica, Magalhães (2015) entende que o processo de humanização depende das mediações que são oportunizadas aos homens. O homem torna-se social na medida em que se apropria do conhecimento historicamente construído, das formas de conduta, dos acordos sociais, representações do percurso coletivo, etc.; apropriações "originadas e produzidas pelos indivíduos que têm precedido o que coexiste com ele, e as assimila (mais ou e menos universalmente) à sua vida e à sua atividade" (MARKUS, 1974, p. 27 apud MAGALHÃES, 2015, p. 01).

Essa ideia destaca a importância do caráter histórico-cultural do desenvolvimento humano, isto é, o que move a humanização são as condições históricas concretas, as quais têm, conforme Magalhães (2015), caráter decisivo nas relações sociais estabelecidas, na atividade humana objetivada e produtiva, nos modos sociais de ação com os instrumentos culturais e suas condições de vida e educação.

No seu processo de humanização, os homens, em função de suas próprias necessidades, transformam a natureza num movimento definido como trabalho (SAVIANI, 2007). "O homem é, é-o pelo trabalho", o que nos leva afirmar que a essência do homem é o trabalho, ela é um feito humano que "se aprofunda e se complexifica ao longo do tempo". Portanto, "é um processo histórico" (SAVIANI, 2007, p. 157).

Numa perspectiva histórica e ontológica, o processo acima descrito promove a formação da consciência, a adaptação do comportamento e a própria transformação psíquica e seu desenvolvimento estrutural, bem como o pensamento dos homens. Historicamente, os homens se tornam humanos a partir de um processo produzido e desenvolvido ao longo do tempo, por meio de sua própria ação ou trabalho; quanto ao ontológico, o próprio homem é produto dessa ação. Na interlocução dialética, o homem cria e se apropria das formas humanas de existir, as transforma e transforma a si mesmo na passagem à condição de sujeitos sociais, à sua humanidade.

Entretanto, na forma atual do capitalismo, que se caracteriza pela "fragmentação de todas as esferas da vida social, partindo da fragmentação da produção, da dispersão espacial e temporal do trabalho, da destruição dos referenciais que balizam a identidade de classe e as formas da luta de classes" (CHAUí, 2014, p. 3), temos o comprometimento do modo coletivo de produção, portanto, da própria existência humana. Como a essência humana é definida pelo trabalho e como continua sendo verdadeiro que sem trabalho o homem não pode viver, a dinamização da mediação hegemônica de mundo que tem orientado as ações concretas, imprime novos sentidos ao desenvolvimento humano, inclusive ao trabalho dos sujeitos.

Desse modo, a lógica hegemônica, reprodutora da sociedade de classes, faz com que a significação do trabalho humano deixe de ser o meio de transcendência do homem sobre a natureza e sua própria humanização, desnudada a exploração do capital sobre os sujeitos e a transformação do seu trabalho em mercadoria. 
Como consequência, os homens passam a ser controlados e alienados, a partir da apropriação de seu próprio trabalho. Com Marx (1962), entendemos que trabalho qualitativo cria os valores necessários ao ser humano para satisfazer socialmente as suas necessidades físicas e espirituais, mas o trabalho cooptado e expropriado pelo capital o faz perder seu valor ontológico, pois o torna pura e simplesmente quantitativo, mais-valia (valor excedente) apenas para o capital.

O modo de produção capitalista também provocou decisivas mudanças na educação. Se a educação pode ser plenamente identificada com o processo de trabalho, enquanto constituidora e formadora do próprio homem, com a divisão dos homens em classes e a exploração do seu trabalho, a educação passa a ser cindida, ou seja, uma parte fica destinada à classe dominante, que era diferente daquela a que tinha acesso à classe dominada. Na sociedade capitalista consumou-se a separação entre educação e trabalho.

Com efeito, conforme Saviani (2007, p. 157):

[...] é o modo como se organiza o processo de produção portanto, a maneira como os homens produzem os seus meios de vida que permitiu a organização da escola como um espaço separado da produção. Logo, a separação também é uma forma de relação, ou seja: nas sociedades de classes a relação entre trabalho e educação tende a manifestar-se na forma da separação entre escola e produção.

Para o autor, a separação entre educação (ou a escola) e a produção reflete a divisão que se foi processando ao longo da história, sobretudo no que se refere ao trabalho manual e trabalho intelectual. Por esse ângulo, vê-se que a relação trabalho-educação passou a assumir uma dupla identidade: de um lado, uma educação para o próprio processo de trabalho, ou seja, à formação dos trabalhadores, à produção gerida para atender às necessidades de consumo; de outro, uma educação destinada ao trabalho intelectual. Enquanto na primeira dispensa-se o domínio dos respectivos fundamentos teóricos epistemológicos, logo emancipadores; na segunda, prioriza-se amplo domínio teórico, a fim de preparar as elites e representantes da classe dirigente para atuar nos diferentes setores da sociedade.

Daí convivermos, no mínimo, com uma proposta educacional dualista que visa formar os trabalhadores, mas também os futuros dirigentes. $\mathrm{O}$ que também firma a divisão social do trabalho que, ao mesmo tempo, mudou não só a produção da existência humana, mas também a educação e a reorganização das relações sociais.

Então, a educação nunca será neutra e sempre apresentará contradições. Conforme Magalhães (2015, p. 12):

[...] mesmo que a educação na sociedade capitalista se realize hegemonicamente como reprodutora da sociedade de classes, pressupondo e naturalizando a necessidade de uma educação diferenciada para distintos seguimentos da sociedade, em seu interior também se realizam, como forças de resistências a essas tendências, ações que atuam como forças em sentido oposto, construindo possibilidades objetivas de processos de formação, portanto sociais, que não se articulam com a reprodução das relações de dominação, afirmando-se como processo de luta pela emancipação humana.

Nesse sentido, o modo como está organizada a sociedade atual é a referência para a educação e à organização do trabalho. Temos que o princípio do trabalho é imanente à educação, pois ela orienta e determina o processo 
de trabalho, "se constitui basicamente como um mecanismo”, por meio do qual os integrantes da sociedade se apropriam dos elementos culturais e "também instrumentais, para a sua inserção efetiva na própria sociedade”. O processo é dialético, transforma o homem que transforma a sociedade e a si mesmo (SAVIANI, 2007, p. 160), o que nos leva a refletir sobre o trabalho docente.

\section{Trabalho docente: aspectos conceituais}

O conceito de trabalho docente é aqui sustentado conforme Marx (2012): o trabalho é categoria ontológica estruturante do sujeito social, ao que incluímos a descrição de Saviani (2007), para o qual trabalho é práxis, é atividade humana que somente se constitui como tal à medida que transforma objetiva e materialmente

[...] uma dada realidade - mundo natural e social. A efetivação da práxis requer a concorrência das forças naturais do homem e da sua capacidade de pensar, idealizar, projetar, prever finalidades para a ação, isto é, requer que o homem ponha em movimento sua capacidade teórico-prática (QUEIROZ, 2014, p. 44).

Essa capacidade teórico-prática pode ser constatada nas criações humanas ao longo de sua história, daí o caráter histórico da formação, que deveriam ser apropriadas pelo sujeito, daí seu caráter ontológico, o que possibilita a produção do homem pelo homem, sua humanização (QUEIROZ, 2014; MAGALHÃES, 2015). O trabalho em sua forma humana é, pois, a mediação que o homem necessita para construir-se ontológico e historicamente. Mas, para que o trabalho cumpra esse papel, é necessário que na sociedade predomine a liberdade, que seja favorecido sua condição de sujeito, em relação de colaboração, não de dominação, com os demais sujeitos. Infelizmente, “[...] é precisamente isso que falta nas atuais relações sociais que se dão sob a égide do capitalismo, onde o trabalho é subordinado às regras do mercado, leia-se do capital” (PARO, 1999, p. 106).

Na nossa atual condição sócio-histórica, tomar o trabalho enquanto condição ontológica nos é negado. No capitalismo, suas potencialidades concretas são secundarizadas em favor da precedência absoluta do trabalho abstrato, diga-se em favor da possibilidade de criação do valor econômico que serve à sua expansão. Aqui nos encontramos com o trabalho docente.

Queiroz (2014, p. 42), alicerçada na perspectiva marxista, assim define o trabalho docente:

[...] de um modo geral e do ponto de vista filosófico, é concebido, como práxis - investigativa, ética e política -, na condição de mediação no seio da prática social global. Sendo uma das manifestações da educação - que, por sua vez, é uma forma específica de práxis -, o trabalho docente compartilha de sua histórica e complexa finalidade que é a de mediar o processo de constituição do ser humano.

Conforme a autora, trabalho docente é trabalho não material, mas da mesma forma humanizador, quando práxis. Nesse sentido, a prática objetiva e material, conforme abordagem marxista, torna o trabalho tangível, mas, no caso do trabalho docente, que é intangível porque é não-material, não é possível separar o produtor do seu produto portanto trabalho docente, ainda conforme Queiroz (2014, p. 45): 
[...] se caracteriza mais predominantemente como atividade teórica, cuja referência não é diretamente a prática, mas o saber sistematizado, produzido pelos homens em decorrência de sua atividade prático-material e tornado herança cultural que, assimilada e apropriada pelos sujeitos, tem a potência de desenvolver e sustentar a produção de novos saberes e a própria atividade material.

Sendo práxis, o trabalho docente é atividade teórica que, enquanto atividade prática, orienta, alimenta e sustenta a mediação que “atua na transformação de estados mentais, de ideias, de conceitos” dos sujeitos (LIBÂNEO apud QUEIROZ, 2014, p. 46). O trabalho docente se constrói e se transforma e, por meio da práxis, torna a transformação social possível.

No entanto, como o trabalho docente está sujeito às mesmas influências do capital, enquanto categoria ontológica mostra-se alienado e com limitações, o que inviabiliza, em muitos casos, possíveis ações transformadoras. Como a contradição também está presente na ação docente, ao mesmo tempo ela também pode ser rica de possibilidades. A riqueza de possibilidades e as limitações da ação docente encontram parte de suas explicações no entendimento da formação inicial e continuada, uma vez que essa necessita da mediação entre teoria e prática. Isso nos leva a refletir sobre a universidade e o conhecimento produzido.

Santos (2004) analisa que o conhecimento produzido na universidade pública deve ser orientado para dar consistência ao projeto nacional, criar o conhecimento e formar os quadros necessários à sua concretização. Entretanto, segundo o mesmo autor, nos melhores momentos, a liberdade acadêmica e a autonomia universitária também são parte integrante de projetos neoliberais, mesmo quando os criticam severamente. Esse envolvimento é tão profundo que, em muitos casos, se transformou na segunda natureza da produção do conhecimento científico, inclusive dos processos formativos. A tal ponto que, questionar o projeto político nacional, acarretou questionar também o conhecimento que ela produz e a formação que sustenta.

Para o autor, o conhecimento produzido nas universidades públicas pode favorecer mecanismos neoliberais de controle social, por meio da consolidação do consenso ativo. Para se formarem sujeitos livres e emancipados é necessária a centralidade na relação trabalho-educação, com vistas a uma formação que chegue à possibilidade da realização da práxis social. Esse processo diz do conhecimento científico produzido. Trata-se, agora, de explicitarmos como o conhecimento acadêmico se articula com o processo produtivo e com a formação dos sujeitos sociais.

A produção acadêmica apresenta múltiplas contradições que podem referendar a educação como bem público, portanto, com qualidade social. Conforme Souza e Magalhães (2014), o acervo de conhecimentos que a pós-graduação sistematicamente produz gera concepções que ajudam a formar o professor e referendar sua prática. Nesse sentido, o fenômeno da objetivação da produção acadêmica pode ser contraditório, pois, em alguns casos, ajudam a simplificar a relação teoria-prática, trabalho-educação, educação-cultura, com o objetivo de fortalecer o consenso ativo que aliena os sujeitos.

Como ressaltam Shiroma e Santos (2014) apud Evangelista (2014), o consentimento ativo é construído pela criação e disseminação de uma gama de conceitos que são aceitos pela sociedade, como por exemplo: autonomia, participação, avaliação, eficiência, eficácia, cujos significados reforçam a lógica neoliberal. Melhor explicando, no processo da construção das pesquisas, os conceitos se 
tornam compreensíveis na mesma lógica regulatória neoliberal, além de serem fortalecidos como indicadores da qualidade hegemônica da educação.

Isso significa que passam a assumir o significado de qualidade educacional, conforme forjado e difundido pelo Banco Mundial, Unesco e organismos internacionais. E é reforçado por meio do consenso ativo que se constitui como um processo de regulação, cujo objetivo é produzir concordâncias em relação às políticas educacionais.

Para se consolidar, vale-se não apenas de normas claramente explicitadas, mas da aceitação de participação dos pesquisadores, que aprovam e ajudam na concretização efetiva das ideias neoliberais em suas teorizações. Em seu desenvolvimento, as pesquisas incorporam e refletem as dimensões macro e o micro da racionalidade imposta e, para aderir a elas, criam e fortalecem o consenso ativo, ou, para a elas resistir, assumindo a construção da qualidade social para a educação.

Ao final, por meio das defesas de dissertações e teses e suas publicações, o material teórico produzido e as concepções que sustentam (hegemônicas ou contra hegemônicas) fortalecem a racionalidade neoliberal. Estruturam uma "hegemonia discursiva" (SHIROMA, CAMPOS E GARCIA, 2015, p. 2), que transpõem elementos em seus textos, fortalecendo e legitimando um conjunto de informações que estruturam um discurso justificador do consenso ativo.

Segundo Magalhães e Souza (2014, p. 2), o "consenso ativo faz parte das estratégias da classes dominantes para se tornarem também classe dirigente, seja como coerção, ou como concordância, quer dizer assumindo a direção intelectual e moral do processo social”. O consenso ativo é fundamental para a constituição da hegemonia e essencial para a introdução de uma nova sociabilidade na educação, capaz de envolver professores, alunos, dirigentes educacionais, pais, comunidade, em um mesmo projeto político - o neoliberal.

Posteriormente, ao ser publicada, boa parte da produção acadêmica tem materializado a hegemonia discursiva, dando sustentação às atuais políticas, articulando a ideologia, os interesses, valores e perspectivas neoliberais, que têm sido postas aos sujeitos em formação inicial e continuada e que, ao fim e ao cabo, são os que realizam as mudanças no contexto social.

Assim entendendo, optamos por realizar um recorte no que se refere à produção acadêmica publicada na ANPED, entre os anos de 2009 a 2013, Grupo de Trabalho (GT) - Formação de Professores. O recorte se deu em função de entendermos que a maior parte da produção do conhecimento é produzida no âmbito dos programas de pós-graduação e parte significativa é debatida nos encontros da ANPED. Essas publicações têm tom prescritivo e recorrem a argumento de autoridade, por isso dão margem a interpretações e reinterpretações que geram significados e sentidos de vozes discordantes e em disputa.

Nosso recorte demarca um novo terreno de análise, a intertextualidade explicita uma disputa conceitual nos discursos que circulam na ANPED e que atravessam a educação, adentram a profissionalização e o trabalho docente; falam de demandas e metas sociais.

Visando à transformação da realidade estruturada em classes, elegemos o materialismo histórico-dialético como perspectiva crítica norteadora deste trabalho. Com essa base metódica, desenvolvemos uma pesquisa do tipo estudo de caso, de abordagem qualitativa, que tem como principal objetivo compreender, por meio da relação trabalho-educação, a quais sentidos os discursos estão 
referendados, tanto para o trabalho docente, quanto à educação.

\section{Metodologia e posicionamento episte- mológico da pesquisa}

Para compreender a produção acadêmica publicada na ANPEd, a tomamos no movimento de análise pautado na dialética, conforme um grupo de pesquisadores que compõem a REDECENTRO - Rede de pesquisadores sobre professores(as) do Centro-Oeste. Essa é uma ampla rede de pesquisadores de sete programas de pós-graduação em educação da região: UFG, UFU, UFT, UnB, UFMT, UFMS e Uniube. A Rede tem como foco de análise a produção acadêmica, agrega vários projetos de pesquisas, coordenados por pesquisadores com várias formações acadêmicas de contextos da Região Centro-Oeste.

Desenvolvemos uma pesquisa sobre pesquisas, cujos dados são analisados por meio de meta-análise. Metodologicamente, a Rede identifica os estudos sobre professores, sistematiza-os para serem lidos na íntegra. As informações coletadas são catalogadas no instrumento desenvolvido pelo grupo e armazenadas em banco de dados. São categorias de análise construídas pelo grupo: temas desenvolvidos (formação, profissionalização, trabalho docente), tipo e abordagem de pesquisa, método, ideário pedagógico, referencial teórico utilizado.

Neste artigo fizemos o recorte sobre trabalho e trabalho docente, realizado à luz das concepções e perspectivas de estudiosos da Rede. Assumir a base epistemológica da dialética significa que

[...] o método materialista histórico dialético caracteriza-se pelo movimento do pensamento através da materialidade histórica da vida dos homens em sociedade, isto é, trata-se de descobrir (pelo movimento do pensamento) as leis fundamentais que definem a forma organizativa dos homens em sociedade através da história. Este instrumento de reflexão teórico-prática pode estar colocado para que a realidade educacional concreta, pensada, compreendida em seus mais diversos e contraditórios aspectos (PIRES, 1997, p. 83).

O método dialético, conforme proposto por Marx, permite uma reflexão, ocasionando a produção do conhecimento capaz de colaborar criticamente com a temática estudada. O método dialético requer uma abordagem qualitativa de pesquisa.

Para construir nossa categoria de análise - trabalho-educação -, associamos aspectos referentes ao posicionamento epistemológico e político, presentes na introdução, metodologia e considerações finais.

Ao final, buscamos compreender se a relação trabalho-educação propõe a qualidade da educação em sentido social. Metodologicamente seguimos os seguintes passos: a) seleção e leitura do material do GT 8 - Formação de Professores, no que se refere aos trabalhos escolhidos por meio do descritor "trabalho e trabalho docente" presente nos títulos e resumos; b) leitura exploratória e de reconhecimento do material bibliográfico; c) leitura sintética dos artigos selecionados para certificar que os mesmos fazem parte da pesquisa em questão; d) leitura seletiva: determinação dos materiais que de fato nos interessa para o desenvolvimento da pesquisa; e) leitura reflexiva ou crítica: leitura crítica dos artigos recortados para análise; f) leitura interpretativa: momento mais complexo da pesquisa, já que objetiva relacionar as ideias expressas nos artigos pesquisados e selecionados com o problema da pesquisa em questão. 
Assim selecionamos quatro artigos no período: no ano de 2009* foi localizado um artigo; no ano de 2010, um artigo; em 2011, mais um artigo; no ano de $2012 * *$, um artigo; e em 2013 nenhum artigo foi encontrado.
Abaixo o Quadro 1 com os títulos dos artigos selecionados:

Quadro 1: Artigos selecionados

\begin{tabular}{|l|l|}
\hline TÍTULO & ANO \\
\hline A presença da dimensão sociopolítica no trabalho de Formação de Professores & 2009 \\
\hline Os saberes e o trabalho do professor formador num contexto de mudanças & 2010 \\
\hline Da atividade humana entre Paideia e Politeia: saberes, valores e trabalho docente & 2011 \\
\hline O trabalho docente: expectativas e interesses da pesquisa educacional nas últimas décadas do Brasil & 2012 \\
\hline
\end{tabular}

Fonte: Anped 2009-2013.

Após leitura integral dos artigos, buscamos compreender os discursos e conceitos relacionados ao binômio trabalho-educação, em que destacamos o posicionamento epistemológico e político do autor, por entendermos que eles dizem da hegemonia presente nos estudos.

Conforme a teoria de Gramsci citado por Neves e Martins (2010, p. 24):

[...] O exercício da hegemonia é sempre uma relação pedagógica que busca subordinar em termos morais e intelectuais grupos sociais inteiros por meio da persuasão e da educação. Tratase de um conceito que expressa o movimento realizado por uma classe ou fração de classe sobre outras classes e frações de classes para convencer e organizar o consenso em torno de uma concepção particular de mundo (NEVES; MARTINS, 2010, p. 24).

* $\quad$ No ano de 2009 foram localizados 02 artigos com a palavra-chave "trabalho", porém 01 artigo não foi considerado nesta pesquisa, uma vez que a palavra trabalho não carregava em seu sentido o trabalho docente, veja: "Concepções de Formação de Professores nos trabalhos da ANPEd 2003-2007”.
Assim, na apresentação dos dados, vamos tecendo observações e análises do discurso hegemônico produzido. O primeiro artigo analisado "A presença da dimensão sociopolítica no trabalho de Formação de Professores”, ano de 2009, publicado na $32^{\mathrm{a}}$ Reunião da Anped, trata da relação trabalho-educação discutindo o papel sociopolítico

* $\quad$ Em 2012 encontramos dois artigos com a palavra "trabalho" no título. Inicialmente identificamos, selecionamos e analisamos os dois artigos, porém devido à leitura exploratória da pesquisa bibliográfica chegamos à conclusão de que 01 trabalho não faz parte da nossa seleção. O artigo Trabalho, lugar e identidade profissional docente: um estudo de caso em Austin, Baixada Fluminense” é uma pesquisa que analisou as relações entre as características do trabalho e a formação da identidade docente, articulados com o lugar de atuação do professor. Esse artigo traz em sua análise dois sentidos para a palavra trabalho, o primeiro como local de trabalho - espaço físico e geográfico - como as professoras se identificavam com o seu local de trabalho; e o outro sentido é em relação ao trabalho do professor como identidade de seu trabalho - identidade cultural. Esse segundo sentido de trabalho é relacionado o tempo todo com o primeiro, sendo assim, não há posicionamento ou construção de conceito sobre o trabalho docente 
do professor. Sustenta base epistemológica crítica e referenda o mesmo posicionamento político.

[...] É necessário um trabalho coletivo a fim de superar o discurso ingênuo, individualizado, o olhar unilateral, a desvalorização, a descrença e a desesperança tão presentes no trabalho docente hoje. [...] Faz-se necessário o docente se auto pensar como um agente de transformação social, a qual se apresenta de forma insatisfatória. É importante criar movimentos de resistência conjunta nas Universidades, sejam elas públicas ou privadas e isso se faz possível no meio acadêmico se desenvolvermos iniciativas que envolvam a organização e a participação coletiva dos professores, diretores, coordenadores, alunos e de todos os demais envolvidos no processo educativo (NOGUEIRA; BOCK, 2009, p. 09).

Consideramos que a compreensão da dimensão sociopolítica do trabalho docente depende de maneira direta da finalidade a que se propõe o docente [...] em seu trabalho e de como ele percebe a relação entre a educação (escola) e sociedade. Se o docente tem uma visão ingênua dessa relação e não direciona intencionalmente seu trabalho para a transformação social, corre o risco de reproduzir as demandas sociais impostas pela ideologia dominante e pelo senso-comum (NOGUEIRA; BOCK, 2009, p. 12).

$\mathrm{O}$ artigo destaca o professor como agente político, e o trabalho docente como práxis empenhada na transformação da realidade, aquele que deve contribuir com a transformação da realidade social. O sentido da relação trabalho-educação indica que ela não é “salvadora da pátria”, mas contribui para a “formação de um profissional crítico e consciente de seu papel no contexto sociocultural" (NOGUEIRA; BOCK, 2009, p. 10).
O segundo artigo "Os saberes e o trabalho do professor formador num contexto de mudanças”, publicado na $33^{\mathrm{a}}$ Reunião da Anped em 2010, discutiu o trabalho docente do professor dos cursos de licenciatura. O artigo não destaca a relação trabalho-educação pautado na abordagem dialética. Epistemologicamente, não reconhece o trabalho docente como práxis. Inclusive, se referenda na epistemologia da práxis, e a concepção de trabalho é construída com o aporte teórico em Tardif (2002).

Broilo e Cunha (2008, p. 451) expõem que os escritos de Tardif (2002) defendem:

[...] a epistemologia da prática, em que o sujeito posiciona-se através de uma atitude de análise, produção e criação, a respeito de sua ação. Tal base epistemológica pressupõe uma atitude reflexiva no enfrentamento de situações desafiadoras, o que requer um professor atento, que, uma vez inserido no contexto pedagógico, procura desvelar a realidade em sua complexidade, refletindo antes, durante o depois do processo.

O artigo articula o trabalho docente aos condicionantes de saberes docentes, como individualismo docente, precarização do trabalho, estabilidade na carreira e identidade profissional dos docentes, cujos significados traduzem o discurso hegemônico e seu posicionamento político.

O terceiro artigo "Da atividade humana entre Paideia e Politeia: saberes, valores e trabalho docente”, publicado na $34^{\text {a }}$ Reunião da Anped, no ano de 2011, trata-se de uma pesquisa teórica que aborda os saberes docentes. Quanto à relação trabalho-educação, epistemologicamente sugere uma base positivista que trata o trabalho a partir da ergologia, destacando-o a partir da noção de atividade. Vejamos: 
[...] A ergonomia nos convida a analisar o trabalho nos meios profissionais, ligando condições materiais e organizacionais a partir do ponto de vista da atividade real do trabalhador. O trabalho é atividade reguladora individual e coletiva que põe em marcha o sistema em seus acontecimentos aleatórios de todas as ordens, através das antecipações e gestões simultâneas de múltiplos horizontes temporais que se apresentam numa situação profissional (ALVES; CUNHA, 2011, p. 06).

Conforme o trecho destacado, a concepção de trabalho distancia-se da perspectiva dialética de Marx, relaciona trabalho docente e atividade material e organizacional, o que nos diz do posicionamento político dos autores, uma vez que associa trabalho a processos organizacionais.

$\mathrm{O}$ quarto e último artigo analisado " $\mathrm{O}$ trabalho docente: expectativas e interesses da pesquisa educacional nas últimas décadas do Brasil”, publicado em 2012 na 35ª Reunião da Anped, preocupou-se em pesquisar trabalhos e projetos de pesquisa sobre o trabalho docente (TD), evidenciando que a terminologia de trabalho docente utilizada nas publicações, na maioria das vezes, foge ao conceito real, o que traz preocupação para o campo. Para os autores, o uso de uma terminologia variada sobre o trabalho docente,

[...] sem o devido esclarecimento e conceituação pode imputar significados ao TD que descaracterizem sua complexidade, causando assim um reducionismo em seu sentido. Esta redução pode impelir avanços na profissionalização e valorização da carreira docente perante as políticas educativas e a sociedade (GAMA; TERRAZZAN, 2012, p. 01).
E, ainda,

[...] trabalho docente é um conceito mais amplo do que o trabalho didático e, portanto, não se identifica unicamente com ele; sobretudo, quando se aborda a escola como um espaço que deve ser construído coletivamente e gestado com base em princípios democráticos. Essa concepção exige dos professores uma atuação que rompa com o silêncio da sala de aula e com o individualismo pedagógico (GAMA; TERRAZZAN, 2012, p. 02).

A análise realizada pelas autoras traz repercussões para as pesquisas sobre esta temática, as quais precisam incluir, em seu escopo, análises que ultrapassem a dimensão didática do trabalho docente e passem a considerá-la como parte de um trabalho maior e complexo, que pode ser definido e compreendido na diversidade de seus próprios e espaços de realização (GAMA; TERRAZZAN, 2012, p. 05). Embora o artigo faça a crítica dos trabalhos que tratam sobre o trabalho docente, não constrói sua própria concepção, o que configura um problema epistemológico, tendo em vista que a dialética exige a construção adequada de concepções e conceitos, bem como a explicitação do posicionamento político dos autores.

\section{Algumas considerações finais}

Salvas as devidas proporções, pois apenas um trabalho referendou epistemológica e politicamente suas concepções com base na dialética, identificamos que a maioria dos artigos não destacam a intrínseca relação entre trabalho e educação no desenvolvimento dos sujeitos sociais; também não se preocupam em posicionar-se criticamente e politicamente sobre qual processo de humanização estão referendando. Isso significa que se destaca a 
valorização da hegemonia discursiva neoliberal, cujos conceitos parecem ser passivamente consumidos, validando o consenso ativo e o controle deliberado, já instituído pelas bases teóricas sustentadas nas políticas neoliberais e nos trabalhos.

As estratégias de persuasão do leitor estão presentes nos discursos, o que mostra que palavras, ou a falta delas, fazem a diferença. Houve o uso recorrente de termos que dizem da relação trabalho-educação, ou do trabalho docente, como termos que dizem do “bem público”, da “qualidade da educação”, mas contraditoriamente, alinham-se mais estreitamente, no que se refere ao seu conteúdo, às necessidades do setor produtivo.

Outro problema identificado diz respeito à sustentação conceitual sólida, posicionamento epistemológico e político, assim como base metódica clara - aspectos que tornam o conhecimento produzido para o mercado e, no que tange à formação e ao trabalho docente, sustentam sentidos distorcidos, que ajudam grupos dominantes ao expressarem uma retórica discursiva em direção ao consenso social.

Outro aspecto a ser destacado é que a relação trabalho-educação diz da qualidade dos trabalhos, mas também referenda um conceito de qualidade que traduz um discurso reformador, com apelo à participação da sociedade civil, à solidariedade dos voluntários da comunidade, evidenciando a "penetração da ideologia do gerencialismo na educação. Está presente a hegemonia discursiva da conformação, e da produção de um novo léxico educacional híbrido de pedagógico e gerencial” (SHIROMA, CAMPOS, GARCIA, 2015, p. 11), com presença retórica utilitarista.

Nesse processo, a consolidação do consenso ativo oculta uma dimensão valorativa que não é informada sobre a qualidade da educação. Ou seja, de qual qualidade da educação se fala? O que se preconiza?
A partir de uma perspectiva dialética, a qualidade social da educação deve demandar postura crítica e contra hegemônica, uma posição que diz de uma relação trabalho-educação que inspira reflexão sobre o que se demanda na formação dos sujeitos professores e, particularmente, deve afirmar o compromisso social e político da educação (das pesquisas, da produção do conhecimento) no desenvolvimento do trabalho docente como práxis.

Ao tomarmos os textos como forma de partida, objeto de interpretação, buscamos identificar e compreender os sentidos produzidos, por entendermos que eles não ficam apenas nas palavras, estão além delas. Refletem condições sociais particulares que influenciam no contexto social. Por isso a necessidade contínua da análise dos discursos, como uma forma de problematizar a produção do conhecimento e sua relação com a formação dos sujeitos e processo histórico (ORLANDI, 1999).

Conforme a autora, o discurso assim pensado passa a ser compreendido como prática social que nos possibilita apreender as dimensões políticas e ideológicas que constituem as relações de poder. Por isso o que se publica também representa articulações que não são harmônicas ou homogêneas; ao contrário, são relações tensas e contraditórias e influenciam o trabalho docente.

A complexa teia dos discursos produzidos na pós-graduação e publicados no conjunto dos trabalhos da ANPED expressa a luta hegemônica na esfera do discurso. Talvez a vigilância epistemológica na elaboração das pesquisas melhore o domínio da enunciação dos resultados, desfazendo efeitos da ilusão produzida pela lógica neoliberal para a educação e seus fins.

Pensar as pesquisas (publicações da ANPEd), a partir de uma perspectiva histórico-crítica, é compreendê-las como referências 
socioculturais que dizem e legitimam o como devemos (como professores) participar da estrutura social. Nesse sentido, as pesquisas acadêmicas são construtoras de roteiros simbólicos fundamentais na reflexão sobre os sujeitos, suas vidas, e a forma como constroem e mantêm a sociedade. No que diz respeito aos aspectos epistemológicos e políticos relacionados à relação trabalho-educação, há a necessidade de se perceber que os discursos podem estar sendo produzidos como mero reflexo da realidade, como fonte dissimuladora da existência da ideologia no interior de seu próprio funcionamento, fortalecendo um conjunto de conceitos que funcionam como uma forma de dominação.

\section{Referências}

ALVES, W. F.; CUNHA, D. Da atividade humana entre paideia e politeia: saberes, valores e trabalho docente. 34 $4^{\mathrm{a}}$ Reunião Anual da ANPEd - Educação e Justiça Social. Anais... Natal, 2011.

BROILO, C. L.; CUNHA, M. I. Pedagogia universitária e grupos de pesquisa: desafios e perspectivas. In: BROILO, C.; CUNHA, M. I. da. (Orgs.). Pedagogia universitária e produção do conhecimento. $1^{\text {a }}$ ed. Port Anais... o Alegre: EDIPUCRS, v. 3, p. 459464, 2008.

CHAUÍ, M. Contra a universidade operacional: a greve de 2014 (8 de agosto de 2014). Aula Magna USP. São Paulo, 2014.

GAMA, M. E. R.; TERRAZZAN, E. A. O trabalho docente: expectativas e interesses da pesquisa educacional nas últimas décadas no Brasil. 35 $5^{\mathrm{a}}$ Reunião Anual da ANPEd. Anais... Porto de Galinhas, 2012.

MAGAlhãeS, S. M. O. M. Pedagogia histórico-crítica: caminhos de formação e emancipação.Congresso Pedagogia Histórico-
Crítica: educação e desenvolvimento humano. Anais... Bauru, São Paulo: 2015 (Prelo).

MARX, K. O processo de trabalho ou o processo de produção de valores de uso. In: O capital. (Volume 1, Parte Terceira, Capítulo V). 30 ed. Rio de Janeiro: Civilização Brasileira, 2012.

. O capital. Editora Nova Cultural, Coleção Os economistas, 1962, 1988.

NEVES, L. M. W.; MARTINS, A. S. A nova pedagogia da hegemonia e a formação/ atuação de seus intelectuais orgânicos. In: Lúcia Maria Wanderley Neves. (Org.). Direita para o social e esquerda para o capital: intelectuais da nova pedagogia da hegemonia no Brasil. 1ed. São Paulo: Xamã, v. 1, p. 2338, 2010.

NOGUEIRA, M.; BOCK, A. M. B. A presença da dimensão sociopolítica no trabalho de formação de professores. 32 $2^{\mathrm{a}}$ Reunião Anual da ANPEd - Sociedade, cultura e educação: novas regulações?. Anais... Caxambu, 2009.

ORLANDI, E. P. Análise do discurso: princípios e procedimentos. Campinas. São Paulo: Pontes, 1999.

PARO, V. Parem de preparar para o trabalho!!! In: FERRETTI, C. J. et alii (Orgs). Trabalho, formação e currículo: para onde vai a escola. São Paulo: Xamã, 1999.

PIRES, M. F. C. O materialismo históricodialético e a educação. Interface Comunicação, Saúde, Educação, v. 1, n. 1, 1997.

QUEIROZ, V. R. de F. O mal-estar e o bemestar na docência superior a dialética entre resiliência e contestação. 2013. 257f. Tese de Doutorado - Faculdade de Educação da Universidade Federal de Goiás, Goiânia, 2014.

SANTOS, B. S. A universidade no século XXI: para uma reforma democrática e 
emancipatória da universidade. São Paulo: Cortez, 2004.

SAVIANI, D. Trabalho e educação: fundamentos ontológicos e históricos. Revista Brasileira de Educação, v. 12, n. 34 - jan./abr., 2007.

SHIROMA, E. O.; CAMPOS, R. F.; GARCIA, R. M. C. Decifrar textos para compreender a política: subsídios teóricometodológicos para análise de documentos. Disponível em: http://louderdesign.net/ gepeto/artigos/viewdownload/21-artigos/36decifrar-textos-para-compreender-apolitica-subsidios-teorico-metodologicospara-analise-de-documentos.html. Acesso em 15-04-2015.

SHIROMA, E. O.; SANTOS, F. A. Slogans para a construção do consentimento ativo. In: EVANGELISTA, O. (Org.). O que revelam os slogans da política educacional. Araraquara: Junqueira-Marin, 2014.

SOUZA, R. C. C. R. de; MAGALHÃES, S. M. O. (Orgs.). Método e metodologia na pesquisa sobre professores(as). In: Pesquisa sobre professores(as) métodos, tipos de pesquisas, temas, ideário pedagógico e referenciais. Goiânia: Editora PUC-Goiás, 2014. 